\title{
Functional changes in hippocampal synaptic signaling in offspring survivors of a mouse model of intrauterine inflammation
}

Melissa H. Kelley ${ }^{1+}$, Wendy W. Wu ${ }^{1,3+}$, Jun Lei ${ }^{2}$, Michael McLane ${ }^{2}$, Han Xie ${ }^{2}$, Kyle D. Hart ${ }^{1}$, Leonardo Pereira ${ }^{1}$, Irina Burd ${ }^{2^{*}}$ and James Maylie ${ }^{*^{*}}$ (D)

\begin{abstract}
Background: Recent evidence suggests that exposure to intrauterine inflammation causes acute fetal brain injury and is linked to a spectrum of neurobehavioral disorders. In a rodent model of intrauterine inflammation induced by lipopolysaccharide (LPS) exposure in utero, activated microglia can be detected in the hippocampus of offspring survivors, as late as 60 days postnatal (DPN). Given that the hippocampus is important for learning and memory, these results suggest that in utero inflammation underlies long-term cognitive deficits observed in children/survivors.

Methods: An established mouse model of LPS-induced intrauterine inflammation was used to study hippocampal function from offspring at 44-59 DPN. Microgliosis was examined at 45 DPN. Extracellular field recordings of synaptic transmission were performed on acute hippocampal slices.

Results: LPS offspring mice displayed persistent microglial activation and increased CA3-CA1 excitatory synaptic strength, which can be explained in part by an increase in the probability of glutamate release, and reduced long-term synaptic potentiation compared to control mice.

Conclusions: These results offer a mechanistic explanation for the cognitive and behavioral deficits observed in survivors of preterm birth caused by intrauterine inflammation.
\end{abstract}

Keywords: Intrauterine inflammation, Hippocampus, Synaptic transmission, Long-term synaptic potentiation

\section{Background}

Pregnancy and gestation are a critical time for fetal development. Recent evidence suggests that fetal exposure to inflammatory cytokines can have long-lasting effects on postnatal physiology, sometimes lasting into adulthood $[1,2]$. During intrauterine infection/inflammation, proinflammatory cytokines and other mediators can cross the compromised blood-brain barrier and induce activation of microglia and signaling through astrocytes in the fetal brain, causing subsequent production of

\footnotetext{
* Correspondence: iburd@jhmi.edu; mayliej@ohsu.edu

${ }^{\dagger}$ Equal contributors

Integrated Research Center for Fetal Medicine, Gynecology and Obstetrics, Johns Hopkins University, Baltimore, MD 21287, USA

'Obstetrics and Gynecology, Oregon Health \& Science University, Portland, OR 97239, USA

Full list of author information is available at the end of the article
}

reactive oxygen species and cytokines that can lead to glutamate-induced excitotoxicity [3-5]. In addition to the possibility of modulation of neurodevelopment, moderate maternal inflammation also leads to elevated production of serotonin in the placenta, which can disrupt fetal neurodevelopment of serotonin-dependent processes in the forebrain [6].

Preterm children that are exposed to inflammation in utero are at a greater risk for neurological, emotional, and learning disorders [7-9]. Additionally, maternal inflammation has been linked with increased prevalence of autism and experimental animal models mimicking maternal infection and inflammation result in autism-like phenotypes $[10,11]$. Similarly, elevated levels of maternal cytokines, in particular tumor necrosis factor (TNF) $\alpha$, were associated with increasing odds of adult 
schizophrenia and other psychoses in their offspring [12]. These results strongly suggest that in utero inflammation and postnatal cognitive abnormalities are causally linked.

Animal models of intrauterine inflammation include mice, rats, rabbits, and sheep [13, 14]. One wellcharacterized rodent model of preterm birth that mimics human situation of local inflammatory response in the uterus and no overt infection in the dam is intrauterine lipopolysaccharide (LPS) injection [13]. At high doses $(250 \mu \mathrm{g} / 100 \mu \mathrm{l})$, LPS injection results in $>95 \%$ preterm birth and significant fetal brain injury $[1,15]$. Decreasing LPS doses $(50 \mu \mathrm{g} / 100 \mu \mathrm{l})$, however, resulted in $\sim 30 \%$ preterm births, yet with detectable levels of activated microglia as late as 60 days postnatal (DPN) $[2,16]$. In mice exposed to LPS in utero, the volume of the hippocampus, a structure important for learning and memory, is reduced. Whether hippocampal functions are altered in the survivors of preterm birth is currently unclear. In this study, we tested whether exposure to low-dose LPS in utero alters information transfer and storage by the hippocampus in adult survivor mice to understand the cellular mechanisms contributing to cognitive deficits in survivors of preterm birth.

\section{Methods}

\section{Mouse model of intrauterine inflammation}

All animal care and treatment procedures were approved by the Institutional Animal Care and Use Committee, and animals were handled according to the National Institutes of Health guidelines. An established model of intrauterine inflammation was utilized for these studies [15]. Briefly, timed pregnant CD-1 outbred mice were obtained from Charles River Laboratories (Wilmington, MA). Intrauterine injections of $100 \mu \mathrm{l}$ of LPS (from Escherichia coli, 055: B5, Sigma-Aldrich, St. Louis, MO) at a dose of $50 \mu \mathrm{g}$ in $100 \mu \mathrm{L}$ of phosphate-buffered saline (PBS) were administered on embryonic day 17 (E17) of a 19-day gestation period in four independent experiments. Control dams for these experiments received the same volume of intrauterine injection of vehicle. In total, 11 dams were injected with PBS with all litters surviving and 43 dams were injected with LPS with 16 litters surviving. For survival surgery, pregnant mice were anesthetized using isoflurane, and a mini-laparotomy was then performed in the lower abdomen for intrauterine injections. Live pups were separated by sex, and only males were utilized for these studies. While sex could play an important role in the long-term effects of intrauterine inflammation [2], we concentrated on males only in the current study to avoid possible effects of estrus cycle in which circulating hormones could affect hippocampal function [17] as well as potential sex difference in microglia during development [18].

\section{Immunohistochemistry}

At 45 DPN, after the animals were euthanized, $1 \times$ PBS was perfused transcardially, followed by $4 \%$ paraformaldehyde (PFA). The brain from one animal from each dam was dissected and post-fixed in PFA overnight. The next day, specimens were washed with PBS extensively and immersed in 30\% sucrose until saturation, followed by cryosection at $20-\mu \mathrm{m}$ thickness. Sections were incubated overnight at $4{ }^{\circ} \mathrm{C}$ with rabbit anti-Iba-1 (Wako, Richmond, VA) to identify microglia. Donkey anti-rabbit Dylight 568 (Abcam, Cambridge, MA) was applied as the secondary antibody. The sections were further counter-stained with DAPI (Roche, Indianapolis, IN) to identify cell nuclei. Images were obtained using an Axioplan 2 Imaging system (Carl Zeiss, Thornwood, NY) at the bregma level from -1.34 to $-1.70 \mathrm{~mm}$. Quantitative analysis of Iba-1 expression cell numbers and area percentage within CA3-CA1 was performed using ImageJ $1.37 \mathrm{~V}(\mathrm{NIH})$. Each cell was identified as the positive expression (red) in cytoplasm and DAPI (blue) in nucleus. The percentage of Iba-1 expression area was calculated by positive expression area (cell bodies and branches) divided by CA3-CA1 area. The average number of both hippocampi in each hemisphere represented the section counted. The average number of five sections represented the specimen counted.

\section{Hippocampal slice preparation}

Mice were anesthetized with isoflurane and rapidly decapitated. The brain was removed, and $300-\mu \mathrm{m}$ slices from the middle of the hippocampus were cut using a vibrating microtome (VT1000S; Leica Instrument, Leitz) as the brain was immersed in an ice-cold sucrose substituted artificial CSF (aCSF) of the following composition (in $\mathrm{mM}$ ): $119 \mathrm{NaCl}, 26 \mathrm{NaHCO}_{3}, 2.5 \mathrm{KCl}, 1$ $\mathrm{NaH}_{2} \mathrm{PO}_{4}, 1 \mathrm{MgCl}_{2}, 2 \mathrm{CaCl}_{2}$, and 25 dextrose (oxygenated with a carbogen mixture of $95 \% \mathrm{O}_{2}$ and $5 \% \mathrm{CO}_{2}$ ). Slices were held in oxygenated aCSF at $35^{\circ} \mathrm{C}$ for $30 \mathrm{~min}$ and then at room temperature $\left(22-24{ }^{\circ} \mathrm{C}\right)$ for at least $1 \mathrm{~h}$ before recording.

\section{Electrophysiology}

All recordings were made at room temperature. Hippocampal slices were visualized using a fixed-stage, upright microscope (Axio Examiner or Leica DMLFS) equipped with infrared differential interference contrast optics. The recording chamber was continuously perfused with oxygenated aCSF flowing at a rate of $1-2 \mathrm{ml} / \mathrm{min}$. Recording electrodes were pulled from borosilicate pipettes (Sutter Instruments) and had tip resistances of 23.5 $\mathrm{M} \Omega$ when filled with aCSF for extracellular field recordings. Glass stimulating electrodes of approximate resistance of $1 \mathrm{M} \Omega$ were filled with aCSF, connected to a Digitimer constant current stimulus isolation unit 
(AutoMate Scientific, Berkeley, CA), and placed in the middle of the CA1 stratum radiatum to stimulate the CA3 axon collaterals. The CA3 axons were severed to eliminate recurrent excitation within the CA3 subfield. The stimulating and recording electrodes were placed in the middle portion of the CA1 stratum radiatum (approximately equal distance from stratum pyramidal and stratum lacunosum moleculare). Stimulus duration was 0.1-0.2 ms allowing for clear separation of fiber volley (FV) from the preceding stimulus artifact. Long-term potentiation (LTP) of CA3-CA1 excitatory synapses was induced by stimulating CA3 axons with 3 sets of 100 stimuli delivered at $50 \mathrm{~Hz}$.

Recordings were obtained using a Multiclamp 700B amplifier (Molecular Devices) or GeneClamp 500 amplifier (Axon Instruments). Signals were filtered at $3 \mathrm{kHz}$, digitized using a Digidata 1440A interface (Molecular Devices) at $10 \mathrm{kHz}$, and transferred to a computer using pClamp10 software (Molecular Devices) or an ITC-16 (Instrutech Corp., NY) and a computer using Patchmaster (Heka Instruments).

All experiments were performed in the presence of picrotoxin $(100 \mu \mathrm{M})$ and CGP55845 $(2 \mu \mathrm{M}$; both from Tocris Bioscience) to suppress inhibitory synaptic transmission.

\section{Data and statistical analyses}

Voltage traces were analyzed using custom macros written in Igor Pro (WaveMetrics). Statistical analysis was done using $\mathrm{R}$ version 3.3.2 and the geepack package [19]. To account for correlation among hippocampal slices taken from the same animal, we constructed simple GEE models of field excitatory postsynaptic potential (fEPSP) input-output (I/O) relationship, FV-stimulus intensity, paired pulse ratio, and long-term synaptic plasticity with exchangeable correlation structures and, to accommodate the small number of mice relative to the number of slices, a jackknife variance estimator, with intrauterine exposure to LPS as the explanatory variable. We compared Iba-1 expression cell numbers and area percentage using Student's $t$ test with unequal variance.

\section{Availability of data and materials}

All data generated or analyzed during this study are included in this published article. Custom macros written in Igor Pro (WaveMetrics) are available on request (JM).

\section{Results}

\section{Immunohistochemical evaluation}

Mice were exposed to LPS in utero at E17 via intrauterine injection of $50 \mu \mathrm{g}$ LPS in normal saline. Microgliosis was examined in brain cryosections on 45 DPN by immunohistochemistry using antibodies to Iba-1 (microglia) and DAPI (cell nuclei) (Fig. 1a). In CA3-CA1 of the hippocampus, Iba-1 expression cell number was significantly higher in intrauterine LPS-exposed pups compared to control $(115.5 \pm 36.1, n=6$ versus $76.1 \pm 1.6$, $n=5, p=0.044$, Fig. 1b). The percentage of Iba1expression area was also significantly higher among intrauterine LPS-exposed pups $(8.695 \pm 2.831, n=6$ versus $3.002 \pm 0.750 n=5, p=0.003$, Fig. 1c). LPS-treated microglia demonstrated a round shape with fewer branches (amoeboid), indicating the activation of microglia.

\section{Exposure to LPS in utero causes an increase in excitatory synaptic strength in adult offspring}

Acute brain slices were prepared from adult male survivors of LPS exposure and extracellular fEPSPs were measured for CA3-CA1 synapses. Increasing stimulus intensities resulted in increases in the fiber volley $(\mathrm{FV})$ and fEPSP amplitudes. As FVs reflect activation of the CA3 axons (presynaptic effect), the initial slope of the fEPSPs reflects activation of the $\alpha$-amino-3-hydroxy-5methyl-4-isoxazolepropionic acid (AMPA) receptors (postsynaptic effect); the fEPSP slopes (shaded bar) were plotted against the FV amplitudes (dashed line) to yield a fEPSP input-output (I/O) relation (Fig. 2a). The fEPSP $\mathrm{I} / \mathrm{O}$ relations constructed from individual experiments were fit with linear functions, and they reflect presynaptic action potential (AP) generation and the postsynaptic membrane response due to presynaptic AP-induced glutamate release (Fig. 2d). Therefore, we used the slope of the fEPSP I/O relationship as an indicator of synaptic strength (Fig. 2c). Mice that were exposed to LPS in utero displayed a robust increase in synaptic strength (estimated using a GEE model) compared to controls (LPS 0.76 (95\% CI 0.58 to 0.94), $n=20$, from 7 mice, 5 litters; control 0.24 (95\% CI 0.15, 0.34), $n=15$, from 5 mice, 5 litters; $p<0.001)$. These results demonstrate that intrauterine inflammation resulted in increased synaptic strength at hippocampal CA3-CA1 synapse.

These extracellular recordings also allowed for an examination of the CA3 presynaptic excitability as described by plotting the peak of the FV against the stimulus intensity (Fig. 1e). The FV-stimulus intensity relations showed no significant difference between LPS and control mice (Fig. 2f; LPS 0.016 (95\% CI 0.008, 0.023), $n=20$; control 0.018 (95\% CI 0.016, 0.019), $n=15, p=0.543)$. These results suggest that intrinsic excitability of the CA3 axon collaterals was not affected by intrauterine LPS exposure.

\section{Probability of glutamate release is affected in mice exposed to intrauterine LPS}

The increase in fEPSP I/O observed could reflect either pre- and/or post-synaptic changes. To determine whether presynaptic effects on glutamate release contribute to the 

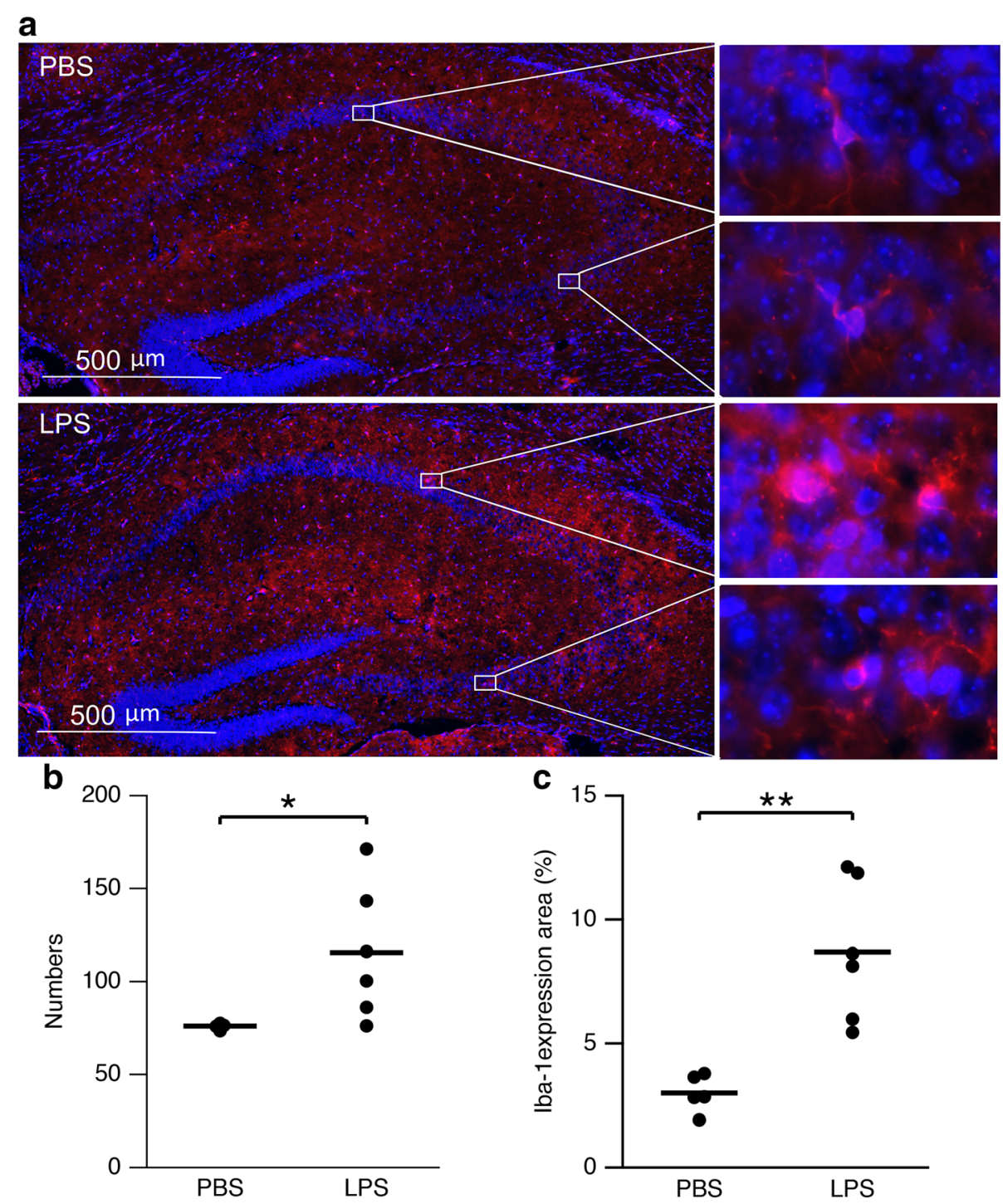

Fig. 1 LPS exposure in utero generated long-term changes in glial appearance in the hippocampus on 45 DPN. a Micrograph showing increased microgliosis (red) in the hippocampus of LPS-exposed mouse. Insets on the right show enlarged image of CA1 and CA3 area. b Scatterplot of microglia cell number in the hippocampus from PBS $(n=5)$ - and LPS $(n=6)$-exposed mice. Asterisks indicate $p<0.05$. c Scatterplot of Iba- 1 expression area in the hippocampus from PBS $(n=5)$ - and LPS $(n=6$-exposed mice. Asterisks indicate $p<0.01$

increased synaptic strength in LPS-exposed mice, extracellular paired-pulse measurements were made by giving two stimuli in close succession $(50 \mathrm{~ms})$ and measuring the slope of the average of 10 fEPSPs for the first and second responses (Fig. 3). The stimulus intensity used for these measurements was set to approximately $50 \%$ of the maximum evoked first response. LPS-exposed mice showed reduced levels of facilitation of the second pulse compared to control mice, as demonstrated by a reduction in the paired pulse ratio or PPR (LPS 1.27 (95\% CI 1.19, 1.34), $n=17$; control 1.54 (95\% CI 1.44, 1.64), $n=9 ; p<0.001$; Fig. 3c). These results suggest greater release of glutamate induced by the first stimulus, hence a reduction in the amount of glutamate release by the second stimulus.
Therefore, the increased synaptic strength observed in LPS-exposed mice is in part mediated by a change in the probability of glutamate release.

\section{Long-term synaptic potentiation is impaired in mice exposed to LPS in utero}

The hippocampus is required for memory formation, and long-term potentiation of the CA3-CA1 excitatory synapses is thought to be the cellular correlate that mediates hippocampus-dependent memory formation [2022]. LTP at these synapses involves a rapid increase in synaptic strength that is largely attributed to increased post-synaptic AMPA receptor insertion [23-25]. The degree of LTP-induced at these synapses was compared 

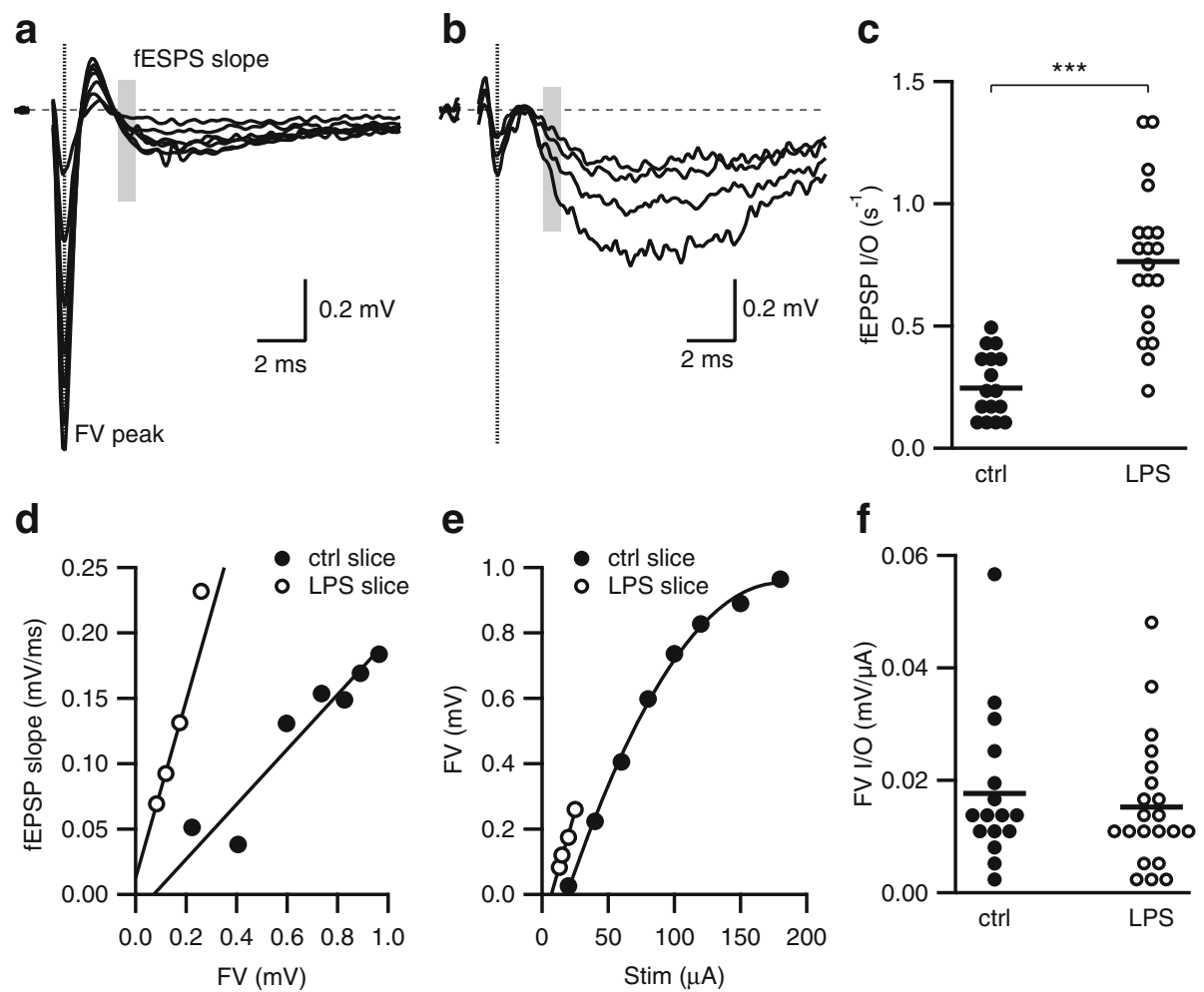

Fig. 2 Exposure to LPS in utero causes a long-term increase in synaptic strength. $\mathbf{a}, \mathbf{b}$ Representative fEPSPs evoked by increasing stimulation intensities from hippocampal slices obtained from adult control mice (a) and mice exposed to LPS in utero (b). Each trace is the average of five consecutively recorded voltage traces. Gray bars highlight the regions where fEPSP initial slopes were measured. Dashed line illustrates the point where the FV peak was measured. The stimulus artifact preceding the FV was blanked out. $\mathbf{d}$ fEPSP slope versus FV relation from a single representative experiment. fEPSP initial slope versus FV relations were fit with linear functions without constraints. The slope derived from the fits $\left(\mathrm{s}^{-1}\right)$ reflects the input-output relation of synaptic transmission (fEPSP I/O). c Scatterplot of fEPSP I/O determined in $\mathbf{d}$ from individual experiments for control- and LPS-exposed mice. Asterisks indicate $p<0.001$. e FV versus stimulus strength (Stim) relationship for a single representative experiment representing the FV input-output relationship (FV I/O). The FV I/O was fit with a quadratic function to calculate the slope of the FV I/O at threshold (FV I/O slope). f Scatterplot of FV I/O slope determined in e for individual experiments demonstrate that CA3 intrinsic excitability and axonal density were not significantly different
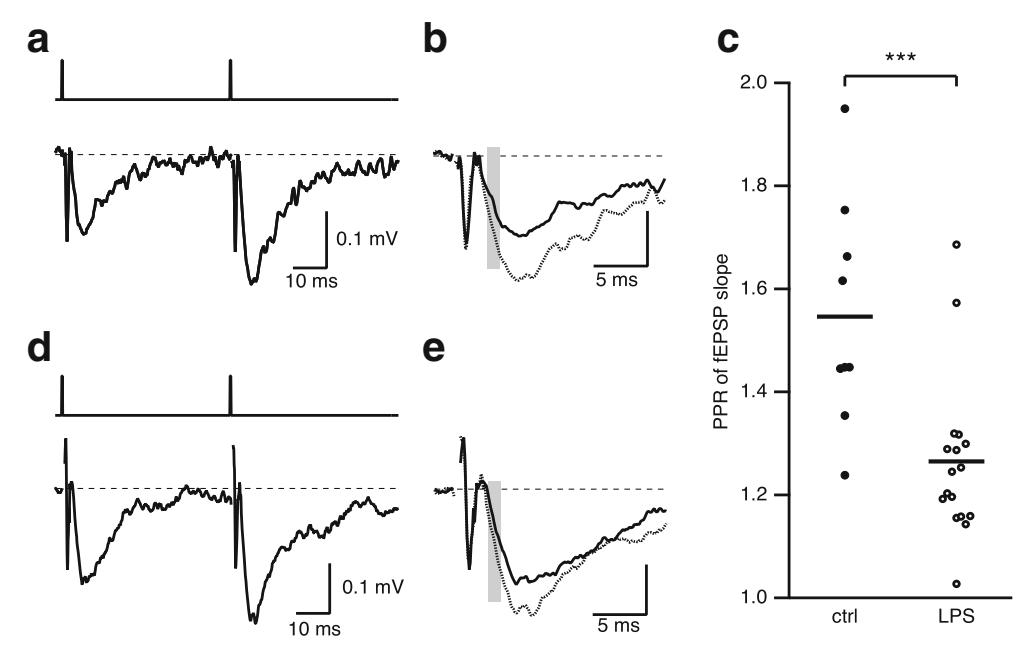

Fig. 3 LPS exposure in utero causes reduced PPR. a, b Representative fEPSPs evoked by paired stimulation separated by $50 \mathrm{~ms}$ (top trace) from hippocampal slices obtained from adult control mice (a) and mice exposed to LPS in utero (d). Each trace is the average of 10 consecutively recorded voltage traces. b, e Overlay of the first (black) and second (dash line) fEPSPs. Gray bars highlight the regions where fEPSP initial slopes were measured. c Scatterplot of PPR determined by measuring the slope of the average of 10 individual trials. Asterisks indicate $p<0.001$ 
between LPS-exposed and control mice. Extracellular fEPSPs were measured at CA3-CA1 synapses using the same protocol as for $\mathrm{I} / \mathrm{O}$ function (Fig. 2), with the initial stimulus intensity set to give $25-50 \%$ of the maximal field response. After achieving 5 min of stable baseline responses, a high-frequency train of stimuli (3 sets of 100 pulses at $50 \mathrm{~Hz}$; Fig. 4a) was administered to induce LTP. The degree of LTP was measured 25-30 min after delivery of the high-frequency train. LPS-exposed mice showed reduced levels of LTP compared to control mice (LPS 138.3 (95\% CI 123.7, 152.9), $n=12$; controls 182.0 (95\% CI 165.6, 198.3), $n=6$; $p<0.001$; Fig. 4. These results suggest inappropriate information storage/coding following LPS exposure.

\section{Discussion}

Children born preterm due to exposure to intrauterine infection or inflammation are at greater risk for developing acute fetal brain injury as well as adverse neurological outcomes including cognitive, motor, and behavioral disabilities such as autism [13, 26-28]. Using a murine model of inflammation and perinatal brain injury, we demonstrated that offspring of pregnant mice exposed to LPS displayed increased synaptic strength, due in part to an increase in the probability of glutamate release from the presynaptic CA3 axon terminals, as evidenced by the reduced PPR ratio. LPS-exposed mice also had lower levels of LTP compared to control mice. This finding could be due to disrupted AMPA receptor trafficking in CA1 pyramidal neurons-a similar cellular change observed in ischemiainduced impairment of LTP [29]. Synaptic dysfunctions and impaired synaptic plasticity at the hippocampal synapses are commonly observed in animal models of disease or toxic substance exposure that exhibit cognitive deficits, including fragile X syndrome [30], Alzheimer's disease [31], accelerated aging [32], and perinatal/acute exposure to lead and polychlorinated biphenyls [33] or marijuana [34]. Thus, the novel findings from the present studies showing changes in hippocampal synaptic transmission and plasticity offer a plausible explanation for the cognitive and behavioral deficits observed in survivors of preterm birth.

The cellular and molecular mechanisms of inflammationinduced fetal brain injury are not fully understood but are likely to involve proinflammatory chemokine and cytokine signaling. During intrauterine inflammation, infectious pathogens likely activate toll-like receptors (TLR) on the surface of cells in the decidua and placental membranes, resulting in the production of proinflammatory cytokines that can cross the compromised blood-brain barrier into the fetal brain where they activate microglia, the primary defense mechanism in the brain $[4,5]$. This process then initiates a cascade of events that leads to increase in proinflammatory cytokines IL-1, IL-6, and TNF $\alpha$ that remain elevated after birth [35-37]. Evidence from adult inflammation models shows that microglia are activated and produce the proinflammatory cytokine TNFo that signals through astrocytes to irreversibly alter synaptic transmission and impair cognition [38-40]. The precise mechanism by which TNF $\alpha$ causes increased synaptic transmission has been studied extensively and may include both pre- and post-synaptic effects that involve retrograde signaling of prostaglandins and nitric oxide [41-43] and synaptic scaling [40]. Importantly, activation of microglia and release of TNF $\alpha$ and the subsequent signaling through astrocytes is the key event leading to behavioral comorbidities as a result of chronic inflammation. Indeed, chronic administration of the microglial/ macrophage activation inhibitor minocycline to the inflamed
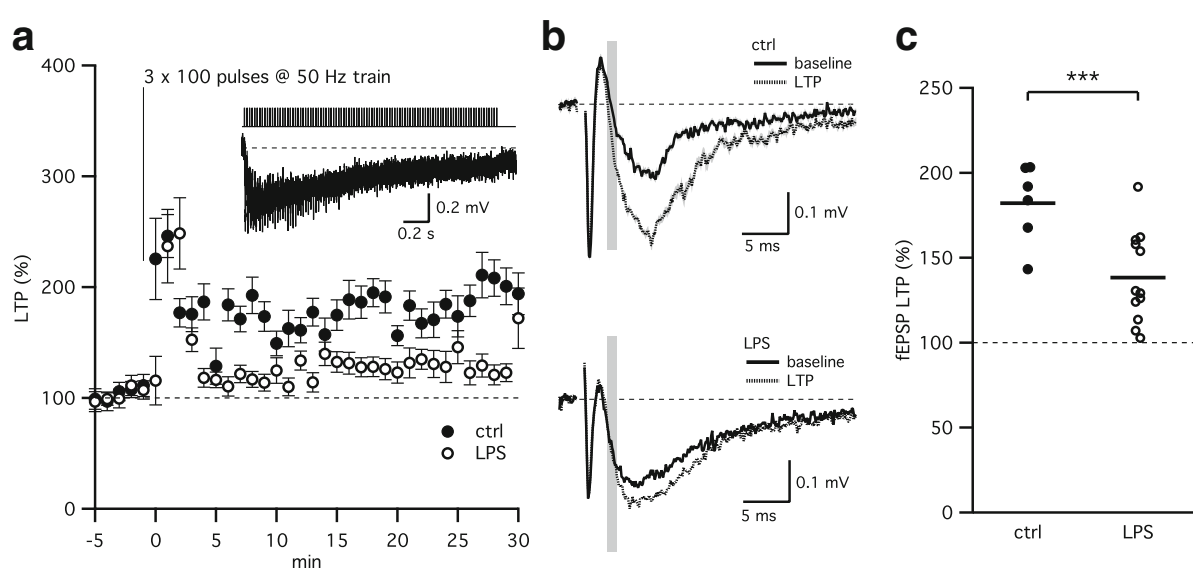

Fig. 4 LPS exposure in utero reduces LTP formation. a Time course (mean \pm SEM) of the normalized fEPSP response (slope) before $\left(-5-0^{\prime}\right)$ and after LTP induction (0-30'). Gray line and inset above demonstrate a 50- $\mathrm{Hz}$ stimulation train and typical response elicited by LTP stimulation protocol $(3 \times 100$ pulses at $50 \mathrm{~Hz}$ ). b Representative average of 10 fEPSPs from a single experiment before (baseline, black) and after LTP induction (LTP, dash). Gray bars highlight the regions where fEPSP initial slopes were measured. c Scatterplot depicting the reduced levels of LTP observed in mice exposed to LPS in utero. Asterisks indicate $p<0.001$ 
animal both lowered the level of TNF $\alpha$ in the hippocampus and completely abolished the effect of peripheral inflammation which induced changes in synaptic transmission and synaptic plasticity [44].

Interestingly, peripheral inflammation is a feature of many adult neurodegenerative diseases and is often associated with marked behavioral changes, including mood disorders, fatigue, cognitive and memory dysfunction, and sleep disturbances. Moreover, the inflammation is capable of aggravating other neurological and neuropsychiatric conditions, including seizure disorders, major depression, Alzheimer's disease, multiple sclerosis, Parkinson's disease, and autism [45]. The changes in synaptic transmission in adult inflammation models are similar to those observed here with prenatal inflammation. It is likely that the persistent activation of microglia 45 DPN in survivors of LPS-treated mice in utero contributes to these changes. Whether they are mediated by TNF $\alpha$ signaling is yet to be determined.

This study not only demonstrates the effects of inflammation on brain function but also reveals a unique longlasting component of the effect of inflammation into adulthood when experienced during a critical period of development. In addition to having implications for neurological effects from peripheral inflammation, these findings extend our understanding of the cognitive deficits in those born preterm as well as other disorders such as autism and schizophrenia.

\section{Conclusion}

Using a murine model of inflammation and perinatal brain injury, we demonstrated that offspring of pregnant mice exposed to LPS displayed altered hippocampal excitatory synaptic function. Synaptic transmission at CA3-CA1 synapses was increased due in part to an increase in the probability of glutamate release from the presynaptic CA3 axon terminals. Importantly, LPSexposed mice also had lower levels of LTP compared to control mice. These novel findings offer a plausible explanation for the cognitive and behavioral deficits observed in survivors of preterm birth caused by intrauterine inflammation.

\section{Abbreviations}

aCSF: Artificial cerebral spinal fluid; AMPA: a-Amino-3-hydroxy-5-methyl-4isoxazolepropionic acid; AP: Action potential; DPN: Days postnatal; fEPSP: Field excitatory postsynaptic potential; FV: Fiber volley; I/O: Inputoutput; LPS: Lipopolysaccharide; LTP: Long-term potentiation; PPR: Paired pulse ratio; TLR: Toll-like receptors; TNF: Tumor necrosis factor

\section{Acknowledgements}

This work was supported by research funding: $\mathrm{NIH}$ and Maternal Fetal Medicine Fund to JM and Sheikh Bugshan Fund and Integrated Research Center for Fetal Medicine Fund to IB.

\section{Availability of data and materials}

All data generated or analyzed during this study are included in this published article.

\section{Authors' contributions}

$L P, I B$, and JM conceived the experiments. JM designed and analyzed the electrophysiological experiments. MHK and WWW contributed equally in performing the electrophysiological experiments. $J \mathrm{~L}$ and $\mathrm{MM}$ generated the intrauterine inflammation animal model. $\mathrm{HX}$ and $\mathrm{JL}$ performed the immunohistochemical analysis. $\mathrm{KDH}$ added the statistical analysis. All authors read and approved the final manuscript.

\section{Ethics approval}

All procedures were approved in accordance with the guidelines of the Institutional Animal Care and Use Committee (IACUC) of the Oregon Health \& Science University (IACUC: IS00003755) and Animal Use and Care Committee at the Johns Hopkins University School of Medicine (MO14M326).

\section{Competing interests}

The authors declare that they have no competing interests.

\section{Publisher's Note}

Springer Nature remains neutral with regard to jurisdictional claims in published maps and institutional affiliations.

\section{Author details}

'Obstetrics and Gynecology, Oregon Health \& Science University, Portland, OR 97239, USA. ${ }^{2}$ Integrated Research Center for Fetal Medicine, Gynecology and Obstetrics, Johns Hopkins University, Baltimore, MD 21287, USA. ${ }^{3}$ Present address: US Food and Drug Administration, Silver Spring, USA.

Received: 3 April 2017 Accepted: 27 August 2017

Published online: 05 September 2017

\section{References}

1. Burd I, Bentz Al, Chai J, Gonzalez J, Monnerie H, Le Roux PD, et al. Inflammation-induced preterm birth alters neuronal morphology in the mouse fetal brain. J Neurosci Res. 2010;88:1872-81.

2. Dada T, Rosenzweig JM, Shammary Al M, Firdaus W, Rebh Al S, Borbiev T, et al. Mouse model of intrauterine inflammation: sex-specific differences in long-term neurologic and immune sequelae. Brain Behav Immun. 2014;38: 142-50.

3. Hagberg H, Mallard C, Ferriero DM, Vannucci SJ, Levison SW, Vexler ZS, et al. The role of inflammation in perinatal brain injury. Nat Rev Neurol 2015;11:192-208.

4. Rocha-Ferreira E, Hristova M. Antimicrobial peptides and complement in neonatal hypoxia-ischemia induced brain damage. Front Immunol. 2015;6:56

5. Breen K, Brown A, Burd I, Chai J, Friedman A, Elovitz MA. TLR-4-dependent and -independent mechanisms of fetal brain injury in the setting of preterm birth. Reprod Sci. 2012;19:839-50.

6. Goeden N, Velasquez J, Arnold KA, Chan Y, Lund BT, Anderson GM, et al. Maternal inflammation disrupts fetal neurodevelopment via increased placental output of serotonin to the fetal brain. J Neurosci. 2016;36:6041-9.

7. Wu YW, Colford JM. Chorioamnionitis as a risk factor for cerebral palsy: a meta-analysis. JAMA. 2000;284:1417-24.

8. Yoon BH, Romero R, Park JS, Kim CJ, Kim SH, Choi JH, et al. Fetal exposure to an intra-amniotic inflammation and the development of cerebral palsy at the age of three years. Am J Obstet Gynecol. 2000;182:675-81.

9. Johnson S, Hollis C, Kochhar P, Hennessy E, Wolke D, Marlow N. Autism spectrum disorders in extremely preterm children. J Pediatr. 2010;156:525-31.e2.

10. Lee BK, Magnusson C, Gardner RM, Blomström Å, Newschaffer CJ, Burstyn I, et al. Maternal hospitalization with infection during pregnancy and risk of autism spectrum disorders. Brain Behav Immun. 2015;44:100-5.

11. Choi GB, Yim YS, Wong H, Kim S, Kim H, Kim SV, et al. The maternal interleukin-17a pathway in mice promotes autism-like phenotypes in offspring. Sci Am Assoc Adv Sci. 2016;351:933-9.

12. Buka SL, Tsuang MT, Torrey EF, Klebanoff MA, Wagner RL, Yolken RH. Maternal cytokine levels during pregnancy and adult psychosis. Brain Behav Immun. 2001:15:411-20

13. Burd I, Balakrishnan B, Kannan S. Models of fetal brain injury, intrauterine inflammation, and preterm birth. Am J Reprod Immunol. 2012;67:287-94.

14. Gavilanes AWD, Strackx E, Kramer BW, Gantert M, Van den Hove D, Steinbusch $\mathrm{H}$, et al. Chorioamnionitis induced by intraamniotic lipopolysaccharide resulted in an interval-dependent increase in central 
nervous system injury in the fetal sheep. Am J Obstet Gynecol. 2009; 200:437. e1-8

15. Elovitz MA, Wang Z, Chien EK, Rychlik DF, Phillippe M. A new model for inflammation-induced preterm birth: the role of platelet-activating factor and Toll-like receptor-4. Am J Pathol. 2003;163:2103-11.

16. Elovitz MA, Brown AG, Breen K, Anton L, Maubert M, Burd I. Intrauterine inflammation, insufficient to induce parturition, still evokes fetal and neonatal brain injury. Int J Dev Neurosci. 2011;29:663-71.

17. Wu WW, Bryant DN, Dorsa DM, Adelman JP, Maylie J. Ovarian hormone loss impairs excitatory synaptic transmission at hippocampal CA3-CA1 synapses. J Neurosci. 2013;33:16158-69.

18. Mccarthy MM, Nugent BM, Lenz KM. Neuroimmunology and neuroepigenetics in the establishment of sex differences in the brain. Nat Rev Neurosci. 2017;22:9005

19. Højsgaard S, Halekoh U, Yan J. The R package geepack for generalized estimating equations. J Stat Softw. 2006;15:1-11.

20. Gruart A, Muñoz MD, Delgado-García JM. Involvement of the CA3-CA synapse in the acquisition of associative learning in behaving mice. J Neurosci. 2006;26:1077-87.

21. Pastalkova E, Serrano P, Pinkhasova D, Wallace E, Fenton AA, Sacktor TC. Storage of spatial information by the maintenance mechanism of LTP. Science. 2006;313:1141-4.

22. Whitlock JR, Heynen AJ, Shuler MG, Bear MF. Learning induces long-term potentiation in the hippocampus. Science. 2006;313:1093-7.

23. Song I, Huganir RL. Regulation of AMPA receptors during synaptic plasticity. Trends Neurosci. 2002;25:578-88.

24. Bredt DS, Nicoll RA. AMPA receptor trafficking at excitatory synapses. Neuron. 2003:40:361-79.

25. Lu W, Man H, Ju W, Trimble WS, MacDonald JF, Wang YT. Activation of synaptic NMDA receptors induces membrane insertion of new AMPA receptors and LTP in cultured hippocampal neurons. Neuron. 2001;29:243-54.

26. Adler DA, Ammanuel S, Lei J, Dada T, Borbiev T, Johnston MV, et al, Circadian cycle-dependent EEG biomarkers of pathogenicity in adult mice following prenatal exposure to in utero inflammation. Neuroscience. 2014;275:305-13.

27. Ranchhod SM, Gunn KC, Fowke TM, Davidson JO, Lear CA, Bai J, et al. Potential neuroprotective strategies for perinatal infection and inflammation. Int J Dev Neurosci. 2015:45:44-54.

28. Petrelli F, Pucci L, Bezzi P. Astrocytes and microglia and their potential link with autism spectrum disorders. Front Cell Neurosci. 2016:10:21.

29. Orfila JE, Shimizu K, Garske AK, Deng G, Maylie J, Traystman RJ, et al. Increasing small conductance Ca2+-activated potassium channel activity reverses ischemia-induced impairment of long-term potentiation. Eur J Neurosci. 2014;40:3179-88.

30. Lauterborn JC, Rex CS, Kramár E, Chen LY, Pandyarajan V, Lynch G, et al. Brain-derived neurotrophic factor rescues synaptic plasticity in a mouse model of fragile X syndrome. J Neurosci. 2007;27:10685-94.

31. Chapman PF, White GL, Jones MW, Cooper-Blacketer D, Marshall VJ, Irizarry $M$, et al. Impaired synaptic plasticity and learning in aged amyloid precursor protein transgenic mice. Nat Neurosci. 1999;2:271-6.

32. López-Ramos JC, Jurado-Parras MT, Sanfeliu C, Acuña-Castroviejo D, Delgado-García JM. Learning capabilities and CA1-prefrontal synaptic plasticity in a mice model of accelerated senescence. Neurobiol Aging 2012, 33:627. e13-26

33. Carpenter DO, Hussain RJ, Berger DF, Lombardo JP, Park H-Y. Electrophysiologic and behavioral effects of perinatal and acute exposure of rats to lead and polychlorinated biphenyls. Environ Health Perspect. 2002; 110(Suppl 3):377-86.

34. Mereu G, Fà M, Ferraro L, Cagiano R, Antonelli T, Tattoli M, et al. Prenata exposure to a cannabinoid agonist produces memory deficits linked to dysfunction in hippocampal long-term potentiation and glutamate release. Proc Natl Acad Sci USA. National Acad Sci; 2003;100:4915-4920.

35. Leitner K, Shammary AI M, McLane M, Johnston MV, Elovitz MA, Burd I. IL-1 receptor blockade prevents fetal cortical brain injury but not preterm birth in a mouse model of inflammation-induced preterm birth and perinatal brain injury. Am J Reprod Immunol. 2014;71:418-26.

36. Cai Z, Pan ZL, Pang Y, Evans OB, Rhodes PG. Cytokine induction in fetal rat brains and brain injury in neonatal rats after maternal lipopolysaccharide administration. Pediatr Res. 2000;47:64-72.

37. Bell MJ, Hallenbeck JM. Effects of intrauterine inflammation on developing rat brain. J Neurosci Res. 2002;70:570-9.
38. Habbas S, Santello M, Becker D, Stubbe H, Zappia G, Liaudet N, et al. Neuroinflammatory TNFa impairs memory via astrocyte signaling. Cell. 2015;163: $1730-41$.

39. Beattie EC, Stellwagen D, Morishita W, Bresnahan JC, Ha BK, Zastrow von M, et al. Control of synaptic strength by glial TNF alpha. Science. 2002;295:2282-5.

40. Stellwagen D, Malenka RC. Synaptic scaling mediated by glial TNF-alpha. Nature. 2006:440:1054-9.

41. Bezzi P, Carmignoto G, Pasti L, Vesce S, Rossi D, Rizzini BL, et al. Prostaglandins stimulate calcium-dependent glutamate release in astrocytes. Nature. 1998;391:281-5.

42. Hardingham N, Dachtler J, Fox K. The role of nitric oxide in pre-synaptic plasticity and homeostasis. Front Cell Neurosci. 2013;7:190.

43. Regehr WG, Carey MR, Best AR. Activity-dependent regulation of synapses by retrograde messengers. Neuron. 2009;63:154-70.

44. Riazi K, Galic MA, Kentner AC, Reid AY, Sharkey KA, Pittman QJ. Microgliadependent alteration of glutamatergic synaptic transmission and plasticity in the hippocampus during peripheral inflammation. J Neurosci. 2015;35: 4942-52.

45. Clark IA, Alleva LM, Vissel B. The roles of TNF in brain dysfunction and disease. Pharmacol Ther. 2010;128:519-48.

\section{Submit your next manuscript to BioMed Central and we will help you at every step:}

- We accept pre-submission inquiries

- Our selector tool helps you to find the most relevant journal

- We provide round the clock customer support

- Convenient online submission

- Thorough peer review

- Inclusion in PubMed and all major indexing services

- Maximum visibility for your research

Submit your manuscript at www.biomedcentral.com/submit
Biomed Central 